First principles investigations of $\operatorname{Ta}_{4} \mathrm{AIX}_{3}(\mathrm{X}=\mathrm{B}, \mathrm{C}, \mathrm{N})$ MAX phase ceramics

\title{
Ayşenur Gencer*
}

Karamanoglu Mehmetbey University, Physics Department, 70100, Karaman, Turkey, ORCID ID orcid.org/0000-0003-2574-3516

\section{ARTICLE INFO}

Article history:

Received 03 May 2020

Received in revised form 17 June 2020

Accepted 10 August 2020

Available online 30 September 2020

Research Article

DOI: 10.30728/boron.731471

\section{Keywords:}

MAX phases,

Density functional theory,

Mechanical properties,

Anisotropic elastic properties,

Thermal properties.

\begin{abstract}
$\mathrm{Ta}_{4} \mathrm{AIX}_{3}(\mathrm{X}=\mathrm{B}, \mathrm{C}, \mathrm{N}) \mathrm{MAX}$ phase ceramics have been examined using first principles calculations in this study. $\mathrm{Ta}_{4} \mathrm{AIX}_{3} \mathrm{MAX}$ phase ceramics have hexagonal crystal structure and the formation energies have been determined for the optimized crystal structures. The elastic constants of $\mathrm{Ta}_{4} \mathrm{AIX}_{3} \mathrm{MAX}$ phase ceramics have been determined and these constants satisfy the mechanical stability criteria. In addition, the mechanical properties such as bulk modulus, shear modulus, etc. have been obtained to reveal the detailed properties of these compounds. The anisotropic elastic properties have been visualized in both $3 \mathrm{D}$ and $2 \mathrm{D}$. Moreover, the thermal properties of $\mathrm{Ta}_{4} \mathrm{AIX}_{3}$ MAX phase ceramics such as thermal expansion coefficient, heat capacity etc. have been studied in 0 to $1000 \mathrm{~K}$ temperature range and 0 to $40 \mathrm{GPa}$ pressure range. In this study, $\mathrm{Ta}_{4} \mathrm{AlB}_{3}$ has been considered for the first time along with $\mathrm{Ta}_{4} \mathrm{AlC}_{3}$ and $\mathrm{Ta}_{4} \mathrm{AIN}_{3}$ compounds and the effect of $\mathrm{X}$ atom to the properties of these compounds have been discussed in detail.
\end{abstract}

\section{Introduction}

MAX phases are interesting compounds due having both metallic and ceramic properties [1]. MAX phases get their name from the $M, A$ and $X$ elements in their structures where $M$ is a transition metal, $A$ is an $A$ group element and $X$ is $C$ and/or $N$ [2]. The chemical formula of MAX phases is $M_{n+1} A X_{n}$ with $n=1,2$ and 3. Moreover, MAX phases with $n=4,5$ and 6 are also investigated in the literature [3-5]. MAX phases have hexagonal crystal structure in the $\mathrm{P}_{3} / \mathrm{mmc}$ space group and MX slabs are interleaved with A layers [6]. This crystal structure results with the strong covalent bonds between $M$ and $X$ atoms and weak bonds between $M$ and $A$ atoms. After the discovery of the MAX phases by Nowotny [7], the MAX phases are synthesis using different methods such as reactive hot pressing [8], self-propagating high-temperature synthesis [9] and spark plasma sintering [10].

MAX phases have high oxidation resistance as a result of their ceramic properties [11]. Also, MAX phases have excellent thermal and electrical conductivities, high shock resistance and great damage tolerance due to their metallic properties [12-14]. MAX phases have been employed for magnetic materials [15], fuel cells [16], nuclear industry [12] that are some examples of the technological applications of the MAX phases. Moreover, the removal of the $A$ atoms in the MAX phases produce a new class of materials as called MXenes [17]. The MXenes are 2D materials and the interest of these materials comes from their special properties for several applications such as photocatalyst [18], energy storage [19] and spintronics [20], etc.

The MAX phases have been investigated in detail with $X$ atom as $C$ and/or N. Theoretically, MAX phases could be formed with $X$ atom as $B$. A limited number of studies have been performed for MAX phase borides where $X$ atom is chosen as $B$ [21-26]. These studies have shown that $B$ substitution for the $X$ atom results with energetically, mechanically and thermodynamically stable MAX phase borides. With the motivation of these studies, $\mathrm{Ta}_{4} \mathrm{AlB}_{3} \mathrm{MAX}$ phase boride with $\mathrm{Ta}_{4} \mathrm{AlC}_{3}$ MAX phase carbide and $\mathrm{Ta}_{4} \mathrm{AIN}_{3}$ MAX phase nitride have been studied using density functional theory and the effect of the $B$ substitution for the $X$ atom in $\mathrm{Ta}_{4} \mathrm{AlX}_{3}$ MAX phase ceramics have been investigated in this study. Recently, $\mathrm{Ta}_{4} \mathrm{AlC}_{3}$ have been synthesized using hot pressing and spark plasma sintering methods [27] and there are several studies both experimentally and theoretically for $\mathrm{Ta}_{4} \mathrm{AlC}_{3}$ ceramic [28-37] and only one theoretical study for $\mathrm{Ta}_{4} \mathrm{AIN}_{3}$ ceramic [38] in the literature. The electronic and mechanical properties of $\mathrm{Ta}_{4} \mathrm{AlC}_{3}$ ceramic were investigated while the mechanical properties of $\mathrm{Ta}_{4} \mathrm{AIN}_{3}$ ceramic was investigated before this study. In the following sections, structural, mechanic, anisotropic elastic and thermal properties of $\mathrm{Ta}_{4} \mathrm{AIX}_{3}$ MAX phase ceramics will be presented and the effect of the $B, C$ and $N$ to these properties will be discussed in detail. 


\section{Computational details}

The $\mathrm{Ta}_{4} \mathrm{AlX}_{3}(\mathrm{X}=\mathrm{B}, \mathrm{C}, \mathrm{N})$ MAX phase ceramics have been studied using the Vienna Ab-initio Simulation Package (VASP) $[39,40]$ that is based on the Density Functional Theory. The projector augmented wave method (PAW) [41,42] has been utilized for the electron-ion interaction with an energy cut off as $550 \mathrm{eV}$. The electron-electron interactions have been considered using the Generalized Gradient Approximation (GGA) of the Perdew-Burke-Ernzerhof (PBE) functional [43]. The k-points have been sampled using a gamma centered mesh [44] and $20 \times 20 \times 2$ k-points have been obtained. The structural optimizations have been performed with an energy convergence criterion as $10^{-11} \mathrm{eV}$ per unit cell and a force convergence criterion as $10^{-10} \mathrm{eV} / \AA$. The valence electron configurations of $\mathrm{B}, \mathrm{C}, \mathrm{N}, \mathrm{Al}$ and Ta have been taken as $2 \mathrm{~s}^{2} 2 \mathrm{p}^{1}$, $2 s^{2} 2 p^{2}, 2 s^{2} 2 p^{3}, 3 s^{2} 3 p^{1}$ and $6 s^{2} 5 d^{3}$, respectively. The crystal structure visualization and X-ray diffraction patterns have been obtained using Vesta software [45]. The mechanical properties have been investigated with the elastic constants that are obtained with stressstrain method within the VASP [46]. Also, the direction dependent mechanical properties have been visualized using ELATE software [47]. The thermal properties have been determined using the GIBBS software [48] where the quasi-harmonic Debye model [49] is employed.

\section{Structural properties of $\mathrm{Ta}_{4} \mathrm{AIX}_{3} \mathrm{MAX}$ phase ceramics}

$\mathrm{Ta}_{4} \mathrm{AlX}_{3}(\mathrm{X}=\mathrm{B}, \mathrm{C}, \mathrm{N}) \mathrm{MAX}$ phase ceramics have hexagonal crystal structure ( $\mathrm{P}_{3} / \mathrm{mmc}, 194$ space group) as shown in Figure $1 \mathrm{a}$. In the literature, $\mathrm{Ta}_{4} \mathrm{AIC}_{3}$ has two phases as called $\alpha$ phase and $\beta$ phase and the only difference between these phases are the positions of the Ta atoms [27]. Moreover, it was found that the $\alpha$ phase of $\mathrm{Ta}_{4} \mathrm{AlC}_{3}$ was more stable than the $\beta$ phase [28]. So, the $\alpha$ phase of $\mathrm{Ta}_{4} \mathrm{AlC}_{3}$ has been considered in this study. In addition, $\mathrm{Ta}_{4} \mathrm{AlB}_{3}$ and $\mathrm{Ta}_{4} \mathrm{AlN}_{3}$ also have the same crystal structure with $\mathrm{Ta}_{4} \mathrm{AlC}_{3}$. These structures have been optimized and the obtained lattice parameters and Wyckoff positions have been listed in Table 1 as well as literature results. The lattice parameters of $\mathrm{Ta}_{4} \mathrm{AlC}_{3}$ are closer to the previous theoretical results and the determined lattice parameters are higher than the experimental results. For $\mathrm{Ta}_{4} \mathrm{AIN}_{3}$, the calculated results are lower than the previous theoretical result that could be due to the different simulation software. Furthermore, the change of the $X$ atom affects the lattice parameters and if $X$ atom changes from $B$ to $N$, a lattice parameter decreases due to the reduction the atomic radius of the $\mathrm{X}$ element and $\mathrm{c}$ lattice parameter increases due to the longer bond length between $\mathrm{Ta}$ and $X$ atom. As can been concluded from Table 1, the lattice parameters of $\mathrm{Ta}_{4} \mathrm{AlC}_{3}$ and $\mathrm{Ta}_{4} \mathrm{AIN}_{3}$ is consistent with the literature and the lattice parameters of $\mathrm{Ta}_{4} \mathrm{AlB}_{3}$ have been determined for the first time and it could be useful for the future studies. In addition, the X-ray diffraction patters of $\mathrm{Ta}_{4} \mathrm{AIX} \mathrm{X}_{3} \mathrm{MAX}$ phase ceramics have been obtained using a $\mathrm{Cu} \mathrm{Ka}$ source with $1.541 \AA$ wavelength and the $\mathrm{X}$-ray diffraction patterns are similar for these compounds as shown in Figure 1b. Also, the $2 \theta$ values are $7.35^{\circ}, 7.29^{\circ}$ and $7.19^{\circ}$ for $\mathrm{Ta}_{4} \mathrm{AlB}_{3}$, $\mathrm{Ta}_{4} \mathrm{AlC}_{3}$ and $\mathrm{Ta}_{4} \mathrm{AlN}_{3}$, respectively.

The thermodynamic stability of these compounds should be considered and the formation energy as listed in Table 1 could be employed for this determination. The formation energy could be calculated using the equation given in Ref. [22] with the total energies of $\mathrm{Ta}_{4} \mathrm{AlX}_{3}$ ceramics and the ground state energies of $\mathrm{Ta}, \mathrm{Al}, \mathrm{B}, \mathrm{C}$ and $\mathrm{N}$ atoms. The calculated formation energies for $\mathrm{Ta}_{4} \mathrm{AIX}{ }_{3}$ MAX phase ceramics have negative values as listed in Table 1 that indicate the thermodynamic stability and synthesizability. As known from the literature, $\mathrm{Ta}_{4} \mathrm{AlC}_{3}$ has already been synthesized and these results also demonstrate that $\mathrm{Ta}_{4} \mathrm{AlB}_{3}$ and $\mathrm{Ta}_{4} \mathrm{AIN}_{3}$ could be synthesized as well. The formation energy difference for $\mathrm{Ta}_{4} \mathrm{AlN}_{3}$ could be arisen from the different simulation software. The thermodynamic stability of $\mathrm{Ta}_{4} \mathrm{AIX}_{3} \mathrm{MAX}$ phase ceramics increases when the $X$ atom changes from $B$ to $N$.
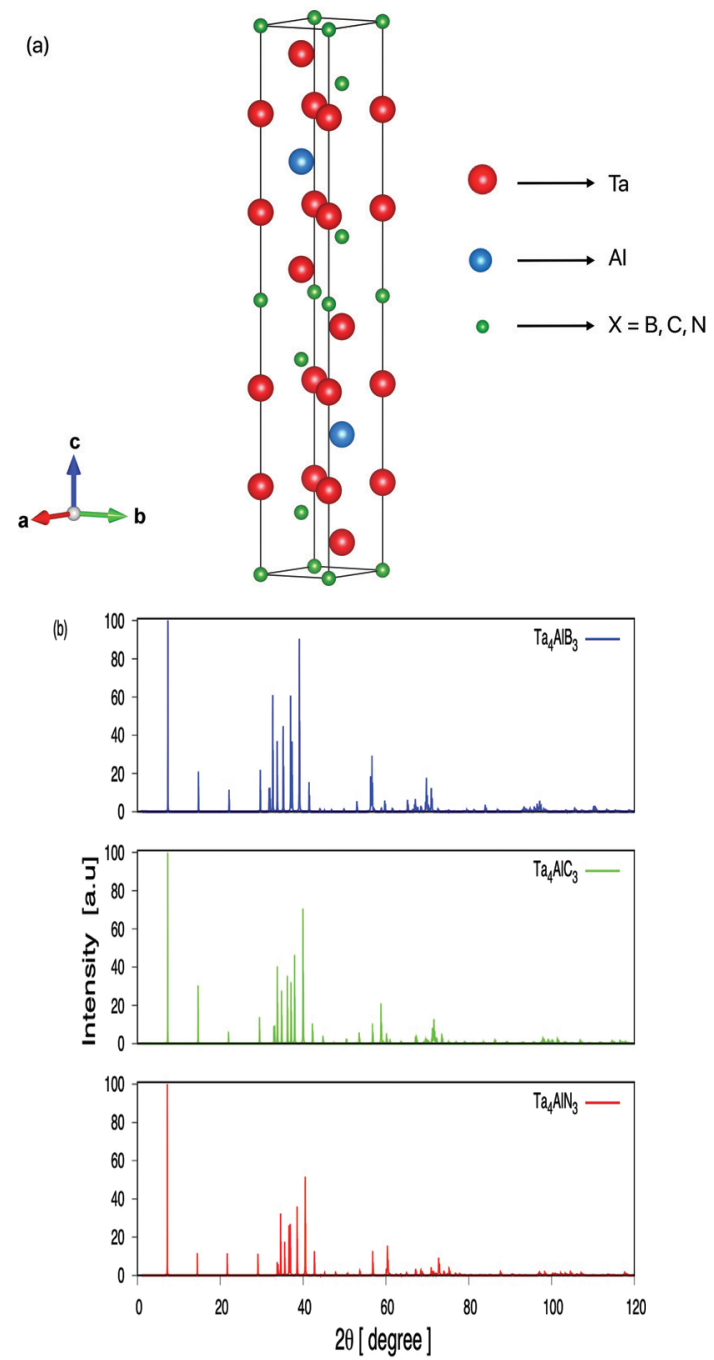

Figure 1. (a) Crystal structure and (b) X-ray diffraction patterns of $\mathrm{Ta}_{4} \mathrm{AlX}_{3}(\mathrm{X}=\mathrm{B}, \mathrm{C}, \mathrm{N})$ MAX phase ceramics. 
Table 1. a and c lattice parameters, formation energy $\left(\Delta E_{F o r}\right)$ and Wyckoff positions of $\operatorname{Ta}_{4} A_{I X}(X=B, C, N)$ MAX phase ceramics.

\begin{tabular}{|c|c|c|c|c|c|}
\hline Compound & Reference & $a(\AA)$ & $c(\AA)$ & $\Delta \mathrm{E}_{\mathrm{For}}$ (eV/atom) & Wyckoff Positions \\
\hline $\mathrm{Ta}_{4} \mathrm{AlB}_{3}$ & This study & 3.25 & 24.08 & -0.55 & $\begin{array}{l}\text { Ta1 }: 4 e(0.0,0.0,0.3398) \\
\text { Ta}_{2}: 4 f(1 / 3,2 / 3,0.4465) \\
\text { Al: } 2 c(1 / 3,2 / 3,1 / 4) \\
B_{1}: 2 a(0.0,0.0,0.0) \\
B_{2}: 4 f(1 / 3,2 / 3,0.8894)\end{array}$ \\
\hline \multirow{7}{*}{$\mathrm{Ta}_{4} \mathrm{AlC}_{3}$} & This study & 3.14 & 24.23 & -0.58 & $\begin{array}{l}\text { Ta1: 4e }(0.0,0.0,0.3427) \\
\text { Ta }_{2}: 4 f(1 / 3,2 / 3,0.4448) \\
\text { Al: } 2 c(1 / 3,2 / 3,1 / 4) \\
\mathrm{C}_{1}: 2 a(0.0,0.0,0.0) \\
\mathrm{C}_{2}: 4 \mathrm{f}(1 / 3,2 / 3,0.8920)\end{array}$ \\
\hline & Exp [27] & 3.11 & 24.10 & & \\
\hline & Exp [30] & 3.11 & 24.10 & & \\
\hline & Exp [31] & 3.09 & 23.71 & & \\
\hline & Theory [28] & 3.14 & 24.16 & & \\
\hline & Theory [34] & 3.13 & 24.27 & & \\
\hline & Theory [35] & 3.19 & 24.55 & & \\
\hline \multirow[t]{2}{*}{$\mathrm{Ta}_{4} \mathrm{AIN}_{3}$} & This study & 3.06 & 24.54 & -1.55 & $\begin{array}{l}\text { Ta1: } 4 \text { e }(0.0,0.0,0.3406) \\
\text { Ta2: } 4 \mathrm{f}(1 / 3,2 / 3,0.4492) \\
\text { Al: } 2 c(1 / 3,2 / 3,1 / 4) \\
\mathrm{N}_{1}: 2 a(0.0,0.0,0.0) \\
\mathrm{N}_{2}: 4 \mathrm{f}(1 / 3,2 / 3,0.8944)\end{array}$ \\
\hline & Theory [38] & 3.15 & 24.88 & -0.58 & \\
\hline
\end{tabular}

\section{Anisotropic elastic and mechanical properties of $\mathrm{Ta}_{4} \mathrm{AIX}_{3}(\mathrm{X}=\mathrm{B}, \mathrm{C}, \mathrm{N})$ MAX phase ceramics}

The mechanical stability of $\mathrm{Ta}_{4} \mathrm{AIX}_{3}(\mathrm{X}=\mathrm{B}, \mathrm{C}, \mathrm{N}) \mathrm{MAX}$ phase ceramics could be determined using the elastic constants. Table 2 lists the calculated elastic constants for these compounds with the available literature results. In order to be a mechanically stable compound, the elastic constants of that compound must satisfy the Born stable criteria $[50,51]$ that can be found in Ref. [52]. The listed elastic constants for $\mathrm{Ta}_{4} \mathrm{AIX}_{3} \mathrm{MAX}$ phase ceramics are satisfied the Born stability criteria; therefore, they are mechanically stable compounds. In addition, the results are coherent with the previous results.

The calculation of the elastic constants is also useful to determine the mechanical properties as listed in Table 3 for $\mathrm{Ta}_{4} \mathrm{AIX}_{3}$ MAX phase ceramics. The bulk modulus ( $B$ ) gives the information of the stiffness of a material and it is defined as the volume change of a material under hydrostatic pressure. The bulk modulus of $\mathrm{Ta}_{4} \mathrm{AIX}_{3} \mathrm{MAX}$ phase ceramics is increased from $\mathrm{Ta}_{4} \mathrm{AlB}_{3}$ to $\mathrm{Ta}_{4} \mathrm{AIN}_{3}$. The shear modulus $(G)$ is defined as the ratio of the shear strain to shear stress and it is important for transverse deformations. As can be seen from Table 3, $\mathrm{Ta}_{4} \mathrm{AlC}_{3}$ has the highest shear modulus among these compounds and it has highest resistance to transverse deformations. Young's modulus (E) also called modulus of elasticity is defined as the length change of a material due to a push or pull. Similar to shear modulus, $\mathrm{Ta}_{4} \mathrm{AlC}_{3}$ has the highest Young's modulus among these compounds. Poisson's ratio $(v)$ is an important parameter to determine the bonding type of a material. The value of 0.25 for the Poisson's ratio indicates the dominantly ionic bonding and 0.1 value indicates the dominantly covalent bonding [22]. Moreover, the Poisson's ratio around 0.33 indicates the metallic bonding and when the value approaches to 0.5 , the plasticity increases for the material [53]. As can be seen from Table 3, $\mathrm{Ta}_{4} \mathrm{AlB}_{3}$ and $\mathrm{Ta}_{4} \mathrm{AlC}_{3}$ have the Poisson's ratio around 0.25 and they have dominantly ionic bonding while $\mathrm{Ta}_{4} \mathrm{AIN}_{3}$ having the Poisson's ratio as 0.332 has metallic bonding. G/B ratio is useful to determine the bonding of the compounds. The $\mathrm{G} / \mathrm{B}$ ratio around $0.3,0.6$ and 1.1 corresponds to metallic bonding, ionic bonding and covalent bonding for the material $[22,53]$. Using these parameters, the same results with the Poisson's ratio have been obtained. The brittle or ductile nature of the materials are crucial and it can be determined using $B / G$ ratio. For this determination,

Table 2. Elastic constants $\left(C_{i j}\right.$ in $\left.\mathrm{GPa}\right)$ for $\mathrm{Ta}_{4} \mathrm{AlX}_{3}(X=B, C, N)$ MAX phase ceramics.

\begin{tabular}{cccccccc}
\hline Compound & Reference & $\mathbf{C}_{11}$ & $\mathbf{C}_{12}$ & $\mathbf{C}_{13}$ & $\mathbf{C}_{33}$ & $\mathbf{C}_{44}$ & $\mathbf{C}_{66}$ \\
\hline Ta $_{4}$ AlB $_{3}$ & This study & 353.57 & 95.83 & 137.74 & 326.61 & 166.60 & 128.87 \\
\multirow{2}{*}{ Ta $_{4}$ AIC $_{3}$} & This study & 442.83 & 163.37 & 152.01 & 378.84 & 175.53 & 139.73 \\
& Theory [28] & 454.00 & 157.00 & 156.00 & 376.00 & 201.00 & 149.00 \\
\multirow{2}{*}{ Ta $_{4}$ AIN $_{3}$} & This study & 349.21 & 224.59 & 200.49 & 365.11 & 161.79 & 62.31 \\
& Theory [38] & 334.00 & 169.00 & 185.00 & 347.00 & 147.00 & 83.00 \\
\hline
\end{tabular}


Table 3. Bulk modulus ( $B$ in $\mathrm{GPa}$ ), Shear modulus ( $\mathrm{G}$ in $\mathrm{GPa}$ ), Young's modulus ( $\mathrm{E}$ in $\mathrm{GPa}$ ), Poisson's ratio (v), $\mathrm{G} / \mathrm{B}$ ratio and $\mathrm{B} / \mathrm{G}$ ratio for $\mathrm{Ta}_{4} \mathrm{AlX}_{3}(\mathrm{X}=\mathrm{B}, \mathrm{C}, \mathrm{N}) \mathrm{MAX}$ phase ceramics.

\begin{tabular}{cccccccc}
\hline Compound & Reference & B & G & E & $v$ & G/B & B/G \\
\hline Ta $_{4} A_{I B}{ }_{3}$ & This study & 197.20 & 133.30 & 326.30 & 0.224 & 0.675 & 1.479 \\
\multirow{2}{*}{ Ta $_{4} A_{I} C_{3}$} & This study & 243.40 & 149.80 & 372.80 & 0.245 & 0.615 & 1.624 \\
& Theory [28] & 247.00 & 161.00 & 397.00 & 0.230 & & \\
\multirow{2}{*}{ TaAAIN $_{3}$} & This study & 257.10 & 97.50 & 259.60 & 0.332 & 0.379 & 2.636 \\
& Theory [38] & 232.00 & 102.00 & 210.00 & & 0.440 & \\
\hline
\end{tabular}

1.75 value is important for $B / G$ ratio. The brittle materials have $B / G$ ratio lower than 1.75 while the ductile materials have higher than 1.75 [22]. As can be seen from Table 3, $\mathrm{Ta}_{4} \mathrm{AlB}_{3}$ and $\mathrm{Ta}_{4} \mathrm{AlC}_{3}$ are brittle materials having $B / G$ ratios as 1.479 and 1.624 while $\mathrm{Ta}_{4} \mathrm{AIN}_{3}$ is a ductile material having $B / G$ ratio as 2.636.

The direction dependent mechanical properties are crucial for technological applications and they give information for the microcracks, plastic deformations, etc. Figure 2 shows the direction dependent Young's modulus, linear compressibility, shear modulus and Poisson's ratio for $\mathrm{Ta}_{4} \mathrm{AlB}_{3}$ in $3 \mathrm{D}$ and $2 \mathrm{D}$. The direction dependent mechanical properties of $\mathrm{Ta}_{4} \mathrm{AlC}_{3}$ and $\mathrm{Ta}$ ${ }_{4} \mathrm{AIN}_{3}$ have not been presented here due to save space in the journal. The spherical or the circular shape indicates the isotropy for that mechanical property while the distorted shapes indicates the anisotropy. Also, the maximum values are shown in blue and the minimum ones are shown in green. For $\mathrm{Ta}_{4} \mathrm{AlB}_{3}$, Young's modulus is isotropic in xy plane while it is anisotropic in $x z$ and $y z$ planes. $\mathrm{Ta}_{4} \mathrm{AlC}_{3}$ and $\mathrm{Ta}_{4} \mathrm{AIN}_{3}$ have similar behavior with $\mathrm{Ta}_{4} \mathrm{AlB}_{3}$ for the direction dependent Young's modulus. Also, the direction dependent linear compressibility is isotropic in all planes for $\mathrm{Ta}_{4} \mathrm{AlB}_{3}$. $\mathrm{Ta}_{4} \mathrm{AIN}_{3}$ has similar behavior with $\mathrm{Ta}_{4} \mathrm{AlB}_{3}$ for direction dependent linear compressibility while the linear compressibility of $\mathrm{Ta}_{4} \mathrm{AlC}_{3}$ is anisotropic in $x z$ and $y z$ planes. The shear modulus and the Poisson's ratio of $\mathrm{Ta}_{4} \mathrm{AlB}_{3}$ have similar behavior and they are isotropic in $x y$ plane while they are anisotropic in $x z$ and $y z$ planes. $\mathrm{Ta}_{4} \mathrm{AlC}_{3}$ and $\mathrm{Ta}_{4} \mathrm{AIN}_{3}$ have similar behavior with $\mathrm{Ta}_{4} \mathrm{AlB}_{3}$ for the direction dependent shear modulus and Poisson's ratio. In addition, the minimum and the maximum values for $\mathrm{Ta}_{4} \mathrm{AIX}_{3}(\mathrm{X}=\mathrm{B}, \mathrm{C}, \mathrm{N}) \mathrm{MAX}$ phase ceramics have been presented in Table $4 . \mathrm{Ta}_{4} \mathrm{AlC}_{3}$ has the highest maximum values for Young's modulus and shear modulus among these compounds as listed in Table 4 consistent with Table 3. Also, $\mathrm{Ta}_{4} \mathrm{AIN}_{3}$ has the highest maximum value for Poisson's ratio as listed in Table 4 and consistent with Table 3. For the linear compressibility, $\mathrm{Ta}_{4} \mathrm{AlB}_{3}$ has the highest maximum value as listed in Table 4.

The thermal properties of $\mathrm{Ta}_{4} \mathrm{AIX}_{3}$ MAX phase ceramics have been investigated using the quasi-harmonic Debye model. The non-equilibrium Gibbs function $\left(G^{*}(V ; P, T)\right)$ is given in Equation 1 where total energy per unit cell is $E(V)$, the constant hydrostatic pressure is $P V$, the Debye temperature is $\theta(V)$ and the vibrational Helmholtz free energy is $A_{V i b}$.

$G^{*}(V ; P, T)=E(V)+P V+A_{V i b}[\theta(V) ; Y]$

The $A_{\text {Vib }}$ could be determined as [54]

$A_{V i b}(\theta, T)=n k T\left[\frac{9 \theta}{8 T}+3 \ln \left(1-e^{-\frac{\theta}{T}}\right)-D\left(\frac{\theta}{T}\right)\right]$

Where $\mathrm{n}$ is the number of atoms per formula unit and $D(\theta / T)$ is the Debye integral. Also, the minimization of the non-equilibrium Gibbs function with respect to volume gives the equation of state and the heat capacity at constant volume $\left(C_{v}\right)$, thermal expansion coefficient $(\alpha)$ and entropy $(S)$ could be determined using Equation 4, Equation 5 and equation 6. In Equation 5, $\gamma$ is the Grüneisen parameter.

$$
\begin{aligned}
& {\left[\frac{\partial G^{*}(V ; P, T)}{\partial V}\right]_{P, T}=0} \\
& C_{v}=n k\left[4 D\left(\frac{\theta}{T}\right)-\frac{3 \theta / T}{e^{\theta / T}-1}\right] \\
& \alpha=\frac{\gamma C_{v}}{B_{T} V} \\
& S=n k\left[4 D\left(\frac{\theta}{T}\right)-3 \ln \left(1-e^{-\theta / T}\right]\right.
\end{aligned}
$$

Table 4. Minimum and maximum values of Young's modulus ( $E$ in $G P a)$, linear compressibility ( $\beta$ ), shear modulus ( $G$ in GPa) and Poisson's ratio (v) for $\mathrm{Ta}_{4} \mathrm{AlX}_{3}(\mathrm{X}=\mathrm{B}, \mathrm{C}, \mathrm{N})$ MAX phase ceramics.

\begin{tabular}{ccccccccc}
\hline \multirow{2}{*}{ Compound } & \multicolumn{2}{c}{ Young's Modulus } & \multicolumn{2}{c}{ Linear Compressibility } & \multicolumn{2}{c}{ Shear Modulus } & \multicolumn{3}{c}{$\begin{array}{c}\text { Poisson's } \\
\text { Ratio }\end{array}$} \\
\cline { 2 - 9 } & $\mathbf{E}_{\min }$ & $\mathrm{E}_{\max }$ & $\beta_{\min }$ & $\beta_{\max }$ & $\mathbf{G}_{\min }$ & $\mathbf{G}_{\max }$ & $v_{\min }$ & $V_{\max }$ \\
\hline $\mathrm{Ta}_{4} \mathrm{AIB}_{3}$ & 242.18 & 366.13 & 1.60 & 1.74 & 99.00 & 166.60 & 0.09 & 0.37 \\
$\mathrm{Ta}_{4} \mathrm{AIC}_{3}$ & 302.60 & 397.84 & 1.24 & 1.65 & 128.47 & 175.53 & 0.12 & 0.31 \\
$\mathrm{Ta}_{4} \mathrm{AIN}{ }_{3}$ & 184.29 & 312.41 & 1.28 & 1.34 & 62.31 & 161.79 & -0.05 & 0.64 \\
\hline
\end{tabular}



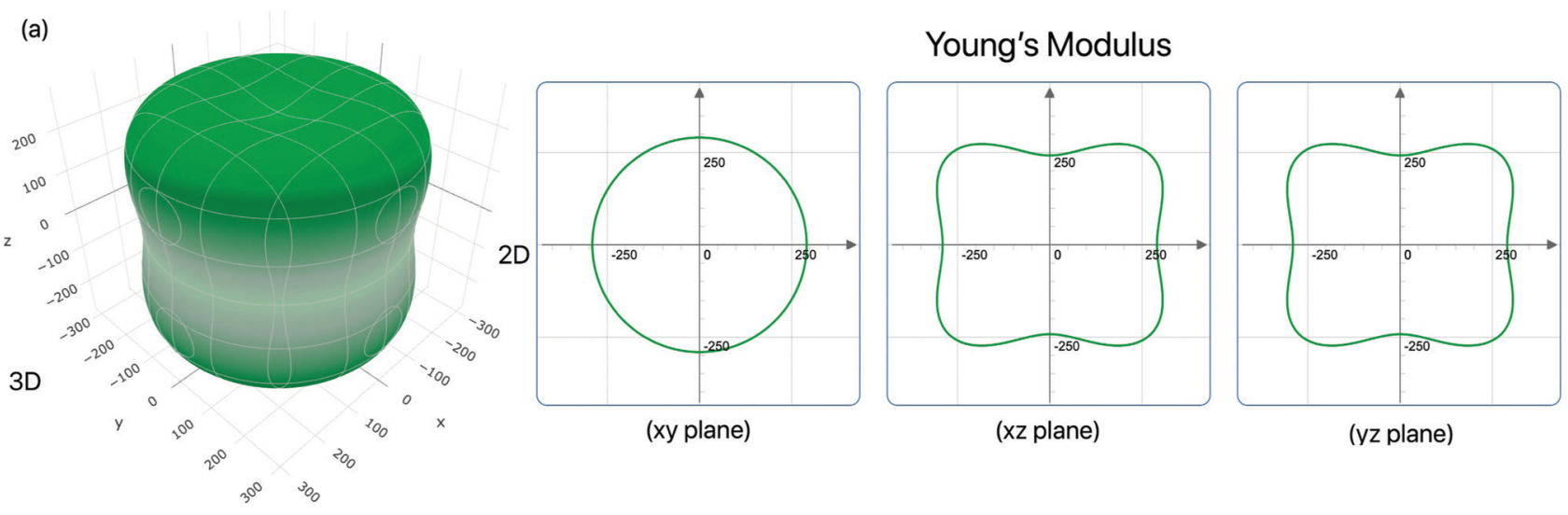
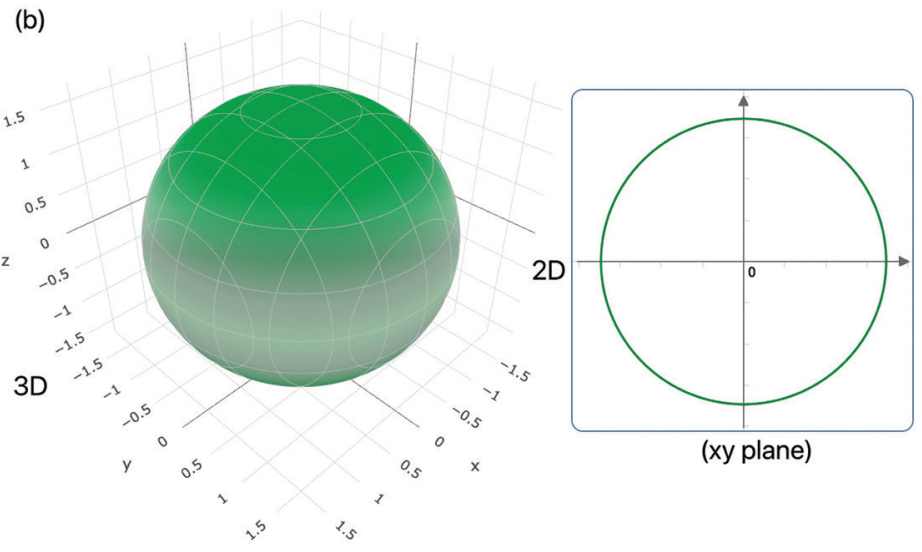

(xy plane)
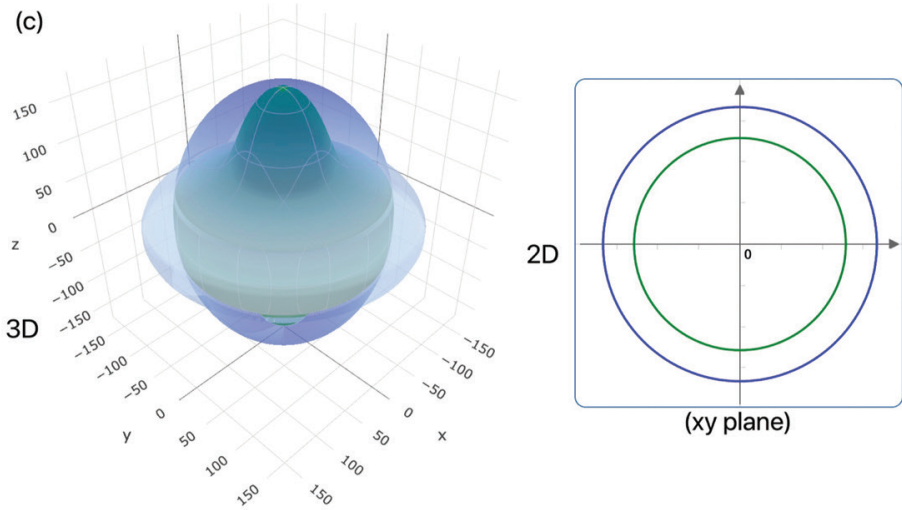

(xy plane)

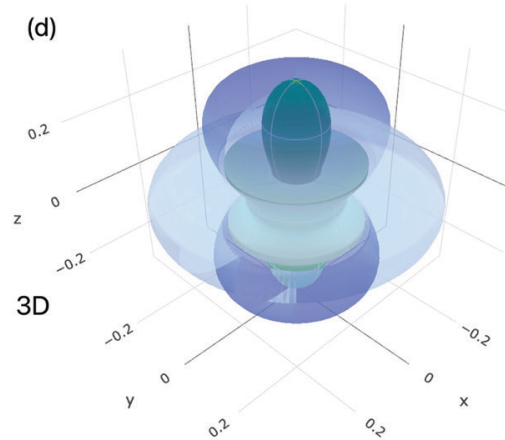

Linear Compressibility

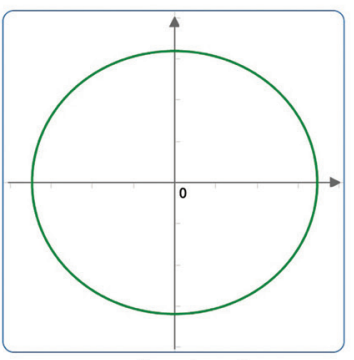

(xz plane)

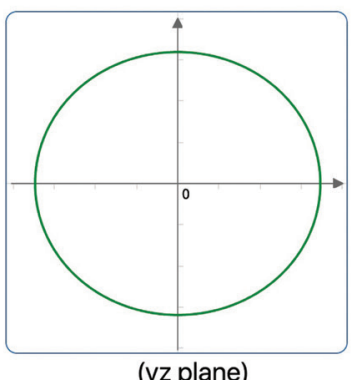

(yz plane)
Shear Modulus

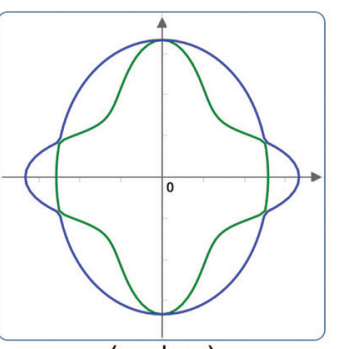

(xz plane)

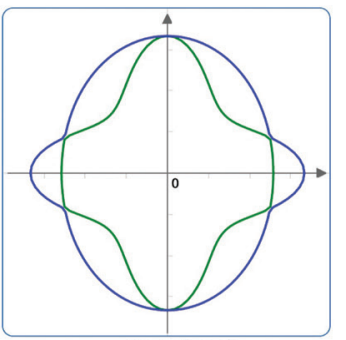

(yz plane)

\section{Poisson's Ratio}

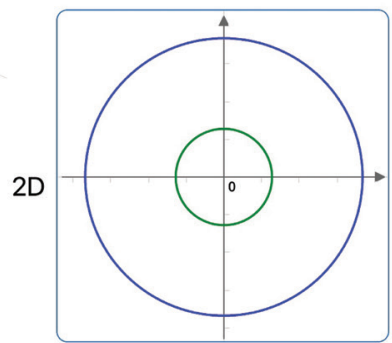

(xy plane)

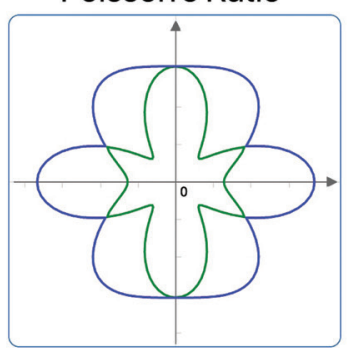

(xz plane)

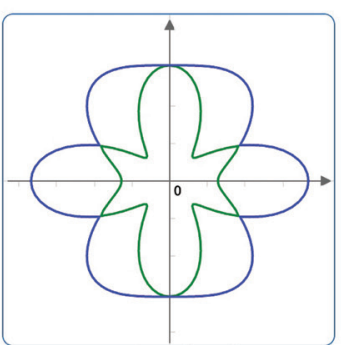

(yz plane)

Figure 2. Direction dependent (a) Young's modulus, (b) linear compressibility, (c) shear modulus and (d) Poisson's ratio of $\mathrm{Ta}_{4} \mathrm{AlB}_{3}$.

The thermal properties such as heat capacity at constant volume, free energy, etc. have been studied in 0 to $1000 \mathrm{~K}$ temperature range and 0 to $40 \mathrm{GPa}$ pressure range using GIBBS software for $\mathrm{Ta}_{4} \mathrm{AIX}_{3} \mathrm{MAX}$ phase ceramics. Figure 3a shows the thermal expansion coefficient for $\mathrm{Ta}_{4} \mathrm{AlB}_{3}$ for $0,10,20,30$ and $40 \mathrm{GPa}$ pressure values. The thermal expansion coefficient increases as the temperature increase while it decreases 
with the pressure increment. This behavior was also observed for $\mathrm{Ta}_{4} \mathrm{AlC}_{3}$ and $\mathrm{Ta}_{4} \mathrm{AIN}_{3}$ compounds and in order to save space, they are not given in here. But, Figure $3 \mathrm{~b}$ shows the thermal expansion coefficient for $\mathrm{Ta}_{4} \mathrm{AlX}_{3}$ compounds at zero GPa pressure to investigate the effect of the change of the $X$ atom to the thermal expansion coefficient. As can be seen from Figure $3 \mathrm{~b}, \mathrm{Ta}_{4} \mathrm{AIN}_{3}$ has the highest thermal expansion among these compounds for low temperature about $500 \mathrm{~K}$ and $\mathrm{Ta}_{4} \mathrm{AIN}_{3}$ and $\mathrm{Ta}_{4} \mathrm{AlB}_{3}$ have thermal expansion coefficients very close to each other at high temperature.

The heat capacity at constant volume is shown in Figure $4 \mathrm{a}$ for $\mathrm{Ta}_{4} \mathrm{AlB}_{3}$ for $0,10,20,30$ and $40 \mathrm{GPa}$ pressure values. The heat capacity increases as the temperature increases and it reaches the DulongPetit limit. The pressure effect on the heat capacity is reverse than the temperature and the heat capacity decreases as the pressure increases as can be seen from Figure 4a. The heat capacity at zero pressure for $\mathrm{Ta}_{4} \mathrm{AIX}_{3} \mathrm{MAX}$ phase ceramics are shown in Figure $4 \mathrm{~b}$ to reveal the effect of $X$ atom to the heat capacity. As can be seen from the figure, $\mathrm{Ta}_{4} \mathrm{AIN}_{3}$ has higher heat capacity than $\mathrm{Ta}_{4} \mathrm{AlB}_{3}$ and $\mathrm{Ta}_{4} \mathrm{AIC}_{3}$ at temperature lower than $800 \mathrm{~K}$ and at the high temperature region, both compounds have similar heat capacities.

The entropy change of $\mathrm{Ta}_{4} \mathrm{AlB}_{3}$ with temperature and pressure change are shown in Figure 5 a. As can be seen from the figure, the entropy increases with the temperature increment while it decreases with the pressure increment. Figure 5b shows the entropy for $\mathrm{Ta}_{4} \mathrm{AIX}_{3}$ MAX phase ceramics at $0 \mathrm{GPa}$ pressure and $\mathrm{Ta}_{4} \mathrm{AIN}_{3}$ has higher entropy than $\mathrm{Ta}_{4} \mathrm{AlB}_{3}$ and $\mathrm{Ta}_{4} \mathrm{AIC}_{3}$ for all temperatures.

Figure 6a shows the free energy for $\mathrm{Ta}_{4} \mathrm{AlB}_{3}$ and the free energy decreases as the temperature increases. Also, the free energy increase when the pressure increases as can be seen from the Figure. Figure $6 \mathrm{~b}$ shows the free energy for $\mathrm{Ta}_{4} \mathrm{AlX}_{3}$ ceramics at $0 \mathrm{GPa}$ pressure and $\mathrm{Ta}_{4} \mathrm{AlC}_{3}$ has the highest free energy among these compounds. This result is consistent with the entropy because $\mathrm{Ta}_{4} \mathrm{AlC}_{3}$ has the lowest entropy among these compounds. (a)

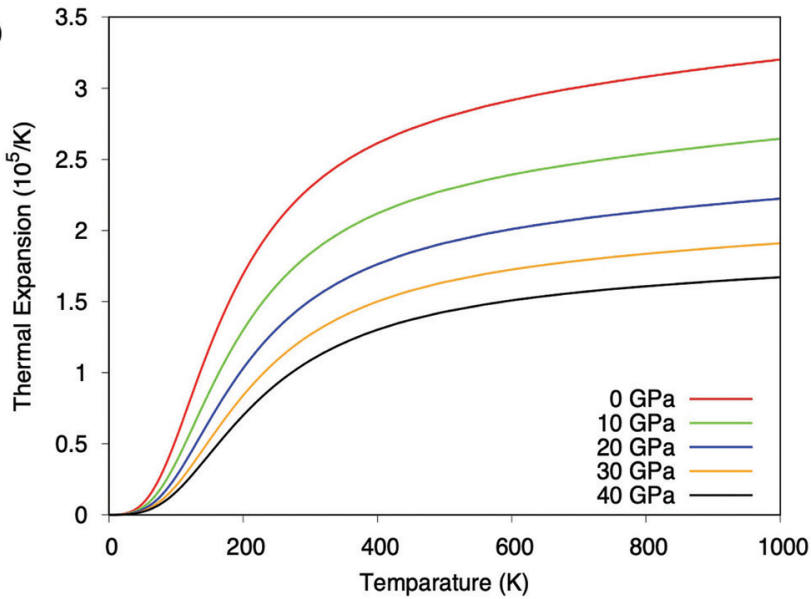

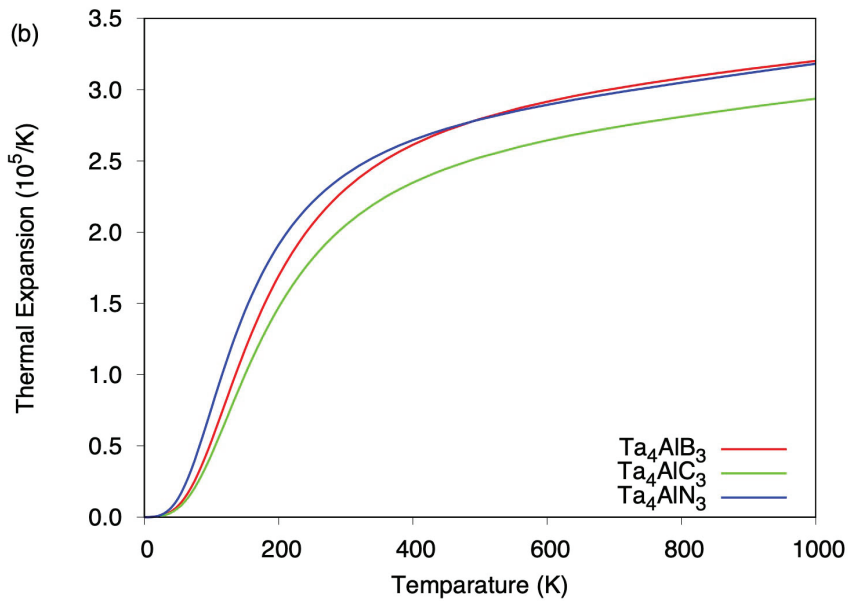

Figure 3. (a) Thermal expansion coefficient for $\mathrm{Ta}_{4} \mathrm{AlB}_{3}$ for $0,10,20,30$ and $40 \mathrm{GPa}$ pressure values and (b) thermal expansion coefficient for $\operatorname{Ta}_{4} \mathrm{AIX}_{3}(\mathrm{X}=\mathrm{B}, \mathrm{C}, \mathrm{N}) \mathrm{MAX}$ phase ceramics at 0 GPa pressure.
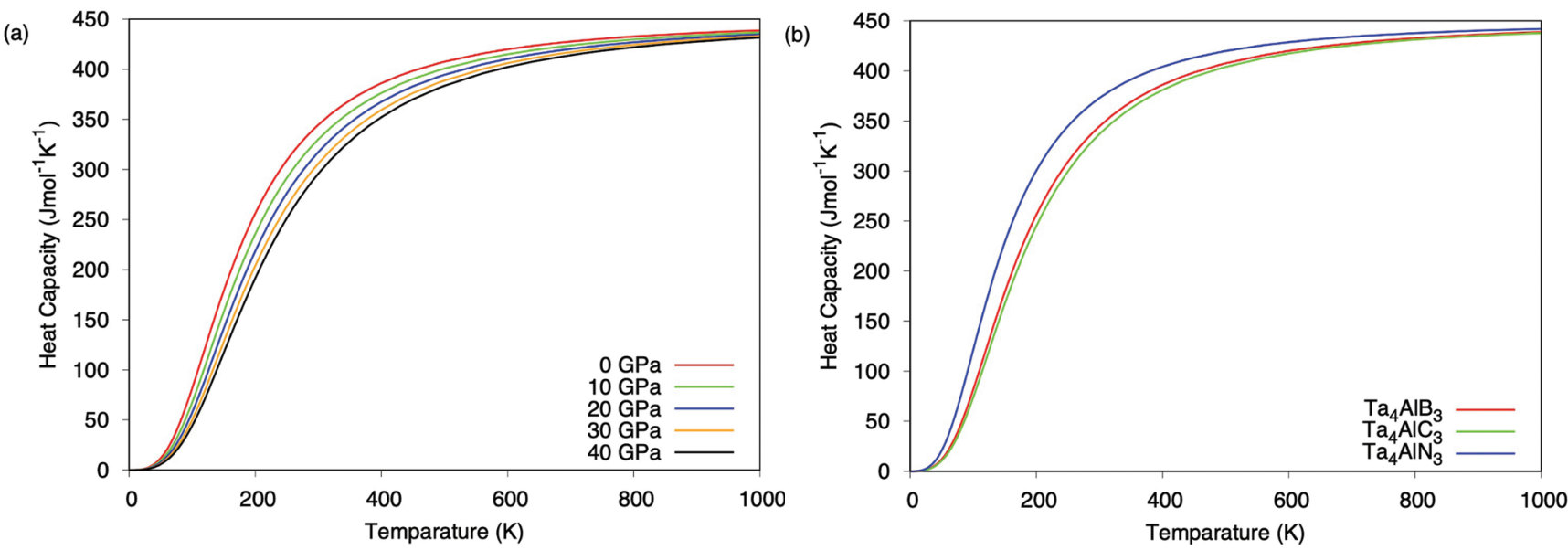

Figure 4. (a) Heat capacity at constant volume for $\mathrm{Ta}_{4} \mathrm{AlB}_{3}$ for $0,10,20,30$ and $40 \mathrm{GPa}$ pressure values and (b) heat capacity at constant volume for $\mathrm{Ta}_{4} \mathrm{AIX}_{3}(\mathrm{X}=\mathrm{B}, \mathrm{C}, \mathrm{N}) \mathrm{MAX}$ phase ceramics at $0 \mathrm{GPa}$ pressure. 
(a)

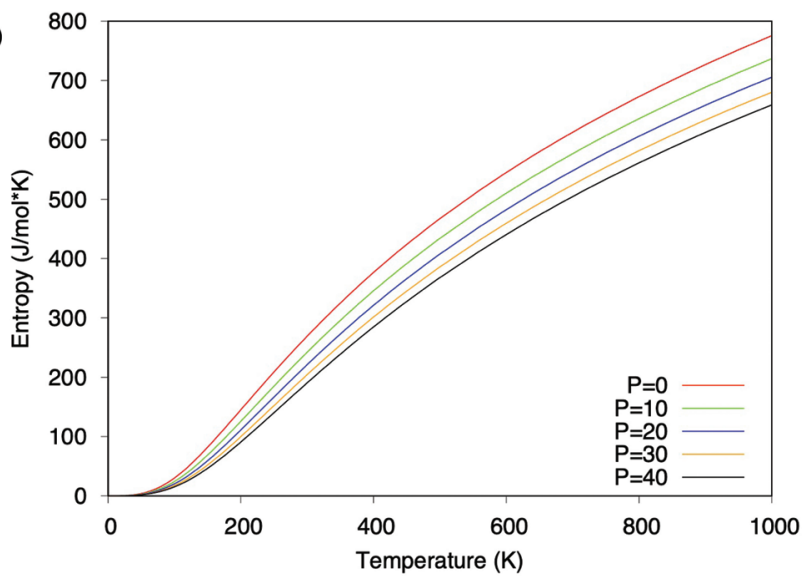

(b)

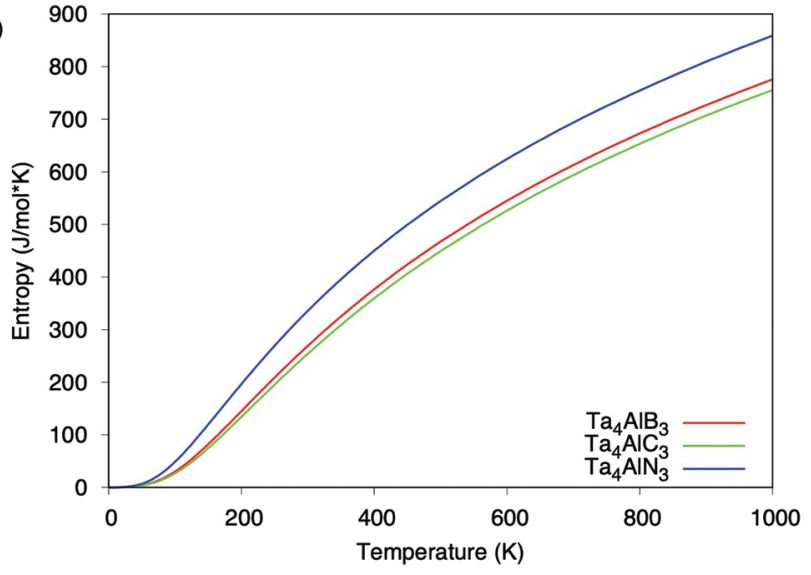

Figure 5. (a) Entropy for $\mathrm{Ta}_{4} \mathrm{AlB}_{3}$ for $0,10,20,30$ and $40 \mathrm{GPa}$ pressure values and (b) entropy for Ta $\mathrm{AIX}_{3}(\mathrm{X}=\mathrm{B}, \mathrm{C}, \mathrm{N}) \mathrm{MAX}$ phase ceramics at 0 Gpa pressure.
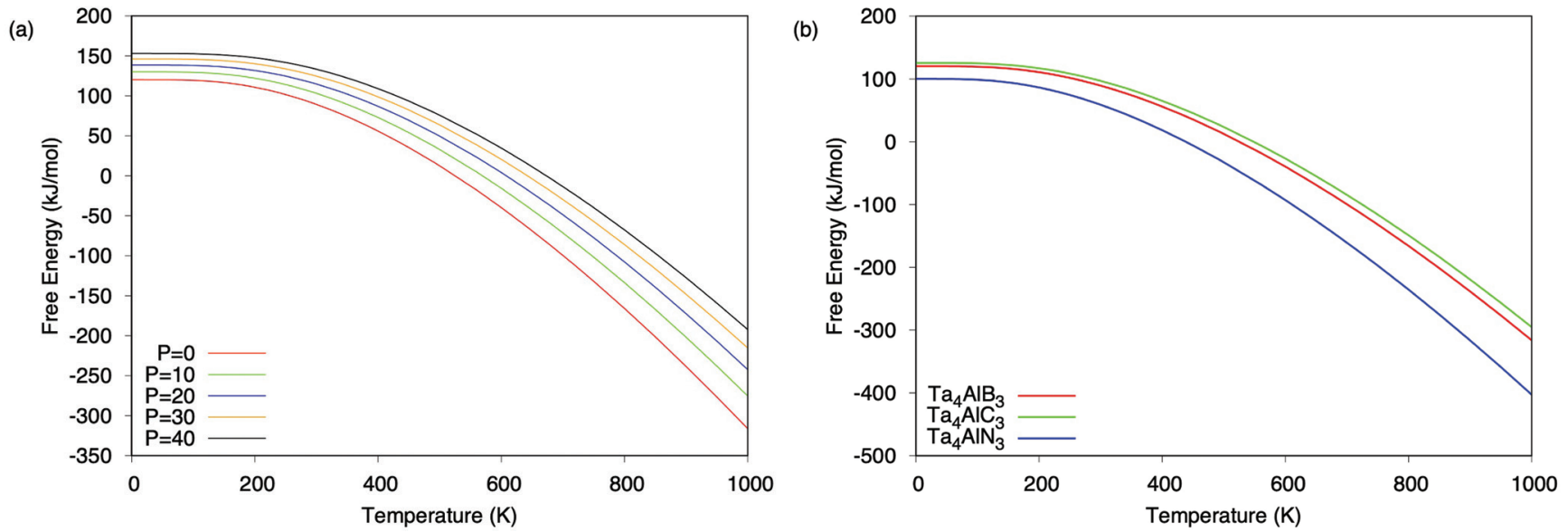

Figure 6. (a) Free energy for $\mathrm{Ta}_{4} \mathrm{AIB}_{3}$ for $0,10,20,30$ and 40 GPa pressure values and (b) free energy for Ta $A I X,(X=B, C, N)$ compounds at $0 \mathrm{GPa}$ pressure.

\section{Conclusion}

$\mathrm{Ta}_{4} \mathrm{AIX}_{3}(\mathrm{X}=\mathrm{B}, \mathrm{C}, \mathrm{N}) \mathrm{MAX}$ phase ceramics have been examined for the electronic, mechanical and thermal properties using Density Functional Theory in this study. $\mathrm{Ta}_{4} \mathrm{AIX}_{3} \mathrm{MAX}$ phase ceramics have been optimized and it has been found that as the $X$ atom changes from $B$ to $N$, a lattice parameter decreases while c lattice parameter increases. The thermodynamic stability of these compounds has been determined with the calculated formation energies that indicate the thermodynamic stability and synthesizability. Also, the thermodynamic stability increases when the $X$ atom changes from $B$ to $N$. Moreover, the mechanical stability of $\mathrm{Ta}_{4} \mathrm{AIX}_{3}$ MAX phase ceramics has been established using the calculated elastic constants with satisfying the mechanical stability. In addition, it has been found that $\mathrm{Ta}_{4} \mathrm{AlB}_{3}$ and $\mathrm{Ta}_{4} \mathrm{AlC}_{3}$ are brittle materials while $\mathrm{Ta}_{4} \mathrm{AIN}_{3}$ is a ductile material. The direction dependent Young's modulus of $\mathrm{Ta}_{4} \mathrm{AlB}_{3}$ is isotropic in $x y$ plane and anisotropic in $x z$ and $y z$ planes while the linear compressibility is isotropic in all planes. Also, the shear modulus and Poisson's ratio of $\mathrm{Ta}_{4} \mathrm{AlB}_{3}$ have similar behavior with Young's modulus and they are isotropic in $x y$ plane and anisotropic in $x z$ and $y z$ planes. In addition, the temperature and pressure dependent thermal properties have been studied in 0 to $1000 \mathrm{~K}$ temperature range and 0 to $40 \mathrm{GPa}$ pressure range. $\mathrm{Ta}_{4} \mathrm{AIN}_{3}$ has the highest thermal expansion coefficient for temperatures about $500 \mathrm{~K}$ and the temperature higher than $500 \mathrm{~K}, \mathrm{Ta}_{4} \mathrm{AlB}_{3}$ has the highest thermal expansion coefficient among these compounds. For the heat capacity at constant volume, $\mathrm{Ta}_{4} \mathrm{AIN}_{3}$ has the highest value lower than $800 \mathrm{~K}$ and for the high temperature, all compounds have similar heat capacity values. $\mathrm{Ta}_{4} \mathrm{AIN}_{4}$ has the highest entropy while $\mathrm{Ta}_{4} \mathrm{AIC}_{3}$ has the highest free energy among these compounds. These study presents the detailed electronic and mechanic properties of $\mathrm{Ta}_{4} \mathrm{AIX}_{3}$ MAX phase ceramics and $\mathrm{Ta}_{4} \mathrm{AlB}_{3}$ is a promising MAX phase boride.

\section{Acknowledgments}

The calculations were fully performed at TUBITAK ULAKBIM, High Performance and Grid Computing Center (TRUBA resources).

\section{References}

[1] Low I. M., Advances In Science and Technology of $\mathrm{M}_{\mathrm{n}+1} \mathrm{AX}_{\mathrm{n}}$ Phases, $1^{\text {st }}$ Edition, Woodhead Pub, 2012. 
[2] Sokol M., Natu V., Kota S., Barsoum M. W., On the chemical diversity of the max phases, Trends Chem., 1 (2), 210-223, 2019.

[3] Lin Z., Zhuo M., Zhou Y., Li M., Wang J., Microstructures and theoretical bulk modulus of layered ternary tantalum aluminum carbides, J. Am. Ceram. Soc., 89 (12), 3765-3769, 2006.

[4] Zhang J., Liu B., Wang J. Y., Zhou Y. C., Low-temperature instability of $\mathrm{Ti}_{2} \mathrm{SnC}$ : $\mathrm{A}$ combined transmission electron microscopy, differential scanning calorimetry, and X-ray diffraction investigations, J. Mater. Res., 24 (1), 39-49, 2009

[5] Uddin M. M., Ali M. A., Ali M. S., Structural, elastic, electronic and optical properties of metastable MAX phase $\mathrm{Ti}_{5} \mathrm{SiC}_{4}$ compound, Indian J. Pure Appl. Phys., 54 (6), 386-390, 2016.

[6] Sürücü G., Erkişi A., The first principles investigation of structural, electronic, mechanical and lattice dynamical properties of the $B$ and $N$ Doped $M_{2} A X$ Type MAX Phases $\mathrm{Ti}_{2} \mathrm{AlB}_{0.5} \mathrm{C}_{0.5}$ and $\mathrm{Ti}_{2} \mathrm{AlN}_{0.5} \mathrm{C}_{0.5}$ Compounds, Boron, 3 (1), 24-32, 2018.

[7] Nowotny V. H., Strukturchemie einiger Verbindungen der Übergangsmetalle mit den elementen $\mathrm{C}, \mathrm{Si}, \mathrm{Ge}$, Sn, Prog. Solid State Chem., 5 (C), 27-70,1971.

[8] Lapauw T., Halim J., Lu J., Cabioc'h T., Hultman L., Barsoum M. W., Lambrinou K., et al., Synthesis of the novel $\mathrm{Zr}_{3} \mathrm{AIC}_{2} \mathrm{MAX}$ phase, J. Eur. Ceram. Soc., 36 (3), 943-947, 2016.

[9] Akhlaghi M., Tayebifard S. A., Salahi E., Shahedi A. M., Schmidt G., Self-propagating high-temperature synthesis of $\mathrm{Ti}_{3} \mathrm{AlC}_{2} \mathrm{MAX}$ phase from mechanicallyactivated Ti/Al/graphite powder mixture, Ceram. Int., 44 (8), 9671-9678, 2018.

[10] Qu L., Bei G., Stelzer B., Rueß H., Schneider J. M., Cao D., Zwaag S. et al., Synthesis, crystal structure, microstructure and mechanical properties of $\left(\mathrm{Ti}_{1}\right.$. $\left.\mathrm{Zr}_{x}\right)_{3} \mathrm{SiC}_{2} \mathrm{MAX}$ phase solid solutions, Ceram. Int., 45 (1), 1400-1408, 2019.

[11] Drouelle E., Brunet V., Cormier J., Villechaise P., Sallot P., Naimi F., Bernard F. et al., Oxidation resistance of $\mathrm{Ti}_{3} \mathrm{AlC}_{2}$ and $\mathrm{Ti}_{3} \mathrm{Al}_{0.8} \mathrm{Sn}_{0.2} \mathrm{C}_{2} \mathrm{MAX}$ phases: A comparison, J. Am. Ceram. Soc., 103 (2), 1270-1280, 2020.

[12] Clark D. W., Zinkle S. J., Patel M. K., Parish C. M., High temperature ion irradiation effects in MAX phase ceramics, Acta Mater., 105, 130-146, 2016.

[13] Gonzalez-Julian J., Mauer G., Sebold D., Mack D. E., Vassen $\mathrm{R}$., $\mathrm{Cr}_{2} \mathrm{AIC}$ MAX phase as bond coat for thermal barrier coatings: Processing, testing under thermal gradient loading, and future challenges, J. Am. Ceram. Soc., 103 (4), 2362-2375, 2020.

[14] Jin S., Su T., Hu Q., Zhou A., Thermal conductivity and electrical transport properties of double-A-layer MAX phase $\mathrm{Mo}_{2} \mathrm{Ga}_{2} \mathrm{C}$, Mater. Res. Lett., 8 (4), 158-164, 2020.

[15] Kirill S., Kolincio K. K., Emelyanov A., Mielewczyk-Gryn A., Gazda M., Roman M., PazniakA., Rodionova V. etal., Evolution of magnetic and transport properties in $\left(\mathrm{Cr}_{1}\right.$ $\left.\mathrm{Mn}_{\mathrm{x}}\right)_{2} \mathrm{AIC}$ MAX-phase synthesized by arc melting technique, J. Magn. Magn. Mater., 493, 165642/1-7, 2020.
[16] Xu J. Zhao M. Q, Wang Y., Yao W, Chen C., Anasori B., Sarycheva A. et al., Demonstration of Li-ion capacity of MAX phases, ACS Energy Lett., 1 (6), 1094-1099, 2016.

[17] Anasori B., Lukatskaya M. R., Gogotsi Y., 2D metal carbides and nitrides (MXenes) for energy storage, Nat. Rev. Mater., 2 (2), 1-17, 2017.

[18] Guo Z., Zhou J., Zhu L., Sun Z., MXene: A promising photocatalyst for water splitting, J. Mater. Chem. A, 4 (29), 11446-11452, 2016.

[19] Pang J. Mendes R. G., Bachmatiuk A., Zhao L., Ta H. Q., Gemming T., Liu H. et al., Applications of 2D MXenes in energy conversion and storage systems, Chem. Soc. Rev., 48 (1), 72-133, 2019.

[20] Gao G., Ding G., L J., Yao K., Wu M., Qian M., Monolayer MXenes: Promising half-metals and spin gapless semiconductors, Nanoscale, 8 (16), 8986-8994, 2016.

[21] Surucu G., Investigation of structural, electronic, anisotropic elastic, and lattice dynamical properties of MAX phases borides: An Ab-initio study on hypothetical $M_{2} A B(M=T i, Z r, H f ; A=A l, G a, I n)$ compounds, Mater. Chem. Phys., 203, 106-117, 2018.

[22] Gencer A., Surucu G., Electronic and lattice dynamical properties of $\mathrm{Ti}_{2} \mathrm{SiB}$ MAX phase, Mater. Res. Express, 5 (7), 076303/1-9, 2018.

[23] Surucu G., Erkisi A., An ab initio study on the investigation of structural, electronic, mechanical and lattice dynamical properties of the $M_{2} A X$ type MAX phases $\mathrm{Sc}_{2} \mathrm{AlB}_{0.5} \mathrm{C}_{0.5}, \quad \mathrm{Sc}_{2} \mathrm{AlB}_{0.5} \mathrm{~N}_{0.5}$ and $\mathrm{Sc}_{2} \mathrm{AlC}_{0.5} \mathrm{~N}_{0.5}$ compounds, Mater. Res. Express, 4 (10), 106520/1-13, 2017.

[24] Chakraborty P., Chakrabarty A., Dutta A., Saha-Dasgupta T., Soft MAX phases with boron substitution: A computational prediction, Phys. Rev. Mater., 2 (10), 103605/1-6, 2018.

[25] Surucu G., Gencer A., Wang X., Surucu O., Lattice dynamical and thermo-elastic properties of $\mathrm{M}_{2}$ AIB $(M=V$, $\mathrm{Nb}, \mathrm{Ta}$ ) MAX phase borides, J. Alloys Compd., 819, 153256/1-10, 2020.

[26] Khazaei M., Arai M., Sasaki T., Estili M., Sakka Y., Trends in electronic structures and structural properties of MAX phases: A first-principles study on $\mathrm{M}_{2} \mathrm{AIC}$ ( $\mathrm{M}=\mathrm{Sc}, \mathrm{Ti}, \mathrm{Cr}, \mathrm{Zr}, \mathrm{Nb}, \mathrm{Mo}, \mathrm{Hf}$, or Ta), $\mathrm{M}_{2} \mathrm{AIN}$, and hypothetical $M_{2} A I B$ phases, J. Phys.: Condens. Matter, 26 (50), 505503/1-12, 2014.

[27] Griseri M., Tunca B., Lapauw T., Huang S, Popescu L., Barsoum M. W., Lambrinou K. et al., Synthesis, properties and thermal decomposition of the $\mathrm{Ta}_{4} \mathrm{AlC}_{3} \mathrm{MAX}$ phase, J. Eur. Ceram. Soc., 39 (10), 2973-2981, 2019.

[28] Deng X. H., Fan B. B., Lu W., First-principles investigations on elastic properties of $\alpha-$ and $\beta-\mathrm{Ta}_{4} \mathrm{AlC}_{3}$, Solid State Commun., 149 (11-12), 441-444, 2009.

[29] Du Y. L., Sun Z. M., Hashimoto H., Tian W. B., Elastic properties of $\mathrm{Ta}_{4} \mathrm{AlC}_{3}$ studied by first-principles calculations, Solid State Commun., 147 (7-8), 246-249, 2008.

[30] Lane N. J., Naguib M., Presser V., Hug G., Hultman L., Barsoum M. W., First-order Raman scattering of the MAX phases $\mathrm{Ta}_{4} \mathrm{AlC}_{3}, \mathrm{Nb}_{4} \mathrm{AlC}_{3}, \mathrm{Ti}_{4} \mathrm{AIN}_{3}$, and $\mathrm{Ta}_{2} \mathrm{AIC}, \mathrm{J}$. Raman Spectrosc., 43 (7), 954-958, 2012. 
[31] Hu C. Lin Z., He L., Bao Y., Wang J., Li M., Zhouet Y. et al., Physical and mechanical properties of bulk $\mathrm{Ta}_{4} \mathrm{AlC}_{3}$ ceramic prepared by an in situ reaction synthesis/Hot-Pressing Method, J. Am. Ceram. Soc., 90 (8), 2542-2548, 2007.

[32] Wang J., Wang J., Zhou Y., Lin Z., Hu C., Ab initio study of polymorphism in layered ternary carbide $\mathrm{M}_{4} \mathrm{AIC}_{3}(\mathrm{M}$ = V, Nb and Ta), Scr. Mater., 58 (12), 1043-1046, 2008.

[33] Lu W., Deng X., Wang H., Huang H., He L., Electronic structure and chemical bonding of $\alpha-$ and $\beta-\mathrm{Ta}_{4} \mathrm{AlC}_{3}$ phases: Full-potential calculation, J. Mater. Res., 23 (9), 2350-2356, 2008.

[34] Du Y. L., Sun Z. M., Hashimoto H., Tian W. B., Bonding properties and bulk modulus of $\mathrm{M}_{4} \mathrm{AlC}_{3}(\mathrm{M}=\mathrm{V}, \mathrm{Nb}$, and Ta) studied by first-principles calculations, Phys. status solidi B, 246 (5), 1039-1043, 2009.

[35] Peng F., Chen D., Yang X., Elasticity and thermodynamic properties of $\alpha-\mathrm{Ta}_{4} \mathrm{AlC}_{3}$ under pressure, J. Alloys Compd., 489 (1), 140-145, 2010.

[36] Li C., Wang Z., Wang C., Effects of aluminum vacancies on electronic structure and optical properties of Ta${ }_{4} \mathrm{AlC}_{3}$ in situ: A first principles study, Phys. B: Condens. Matter, 406 (20), 3906-3910, 2011.

[37] Lane N. J., Eklund P., Lu J., Spencer C. B., Hultman L., Barsoum M. W., High-temperature stability of $\alpha-\mathrm{Ta}_{4} \mathrm{AlC}_{3}$, Mater. Res. Bull., 46 (7), 1088-1091, 2011.

[38] Li C., Wang Z., First principles prediction of structural and mechanical properties of the nanolaminate compound $\mathrm{M}_{4} \mathrm{AlN}_{3}(\mathrm{M}=\mathrm{V}, \mathrm{Nb}$, and $\mathrm{Ta})$, Phys. status solidi B, 248 (7), 1639-1644, 2011.

[39] Kresse G., Furthmüller J., Efficiency of ab-initio total energy calculations for metals and semiconductors using a plane-wave basis set, Int. J. Comput. Mater. Sci., 6 (1), 15-50, 1996.

[40] Kresse G. Furthmüller J., Efficient iterative schemes for ab initio total-energy calculations using a plane-wave basis set, Phys. Rev. B, 54 (16), 11169-11186, 1996.

[41] Kresse G. Joubert D., From ultrasoft pseudopotentials to the projector augmented-wave method, Phys. Rev. B, 59 (3), 1758-1775, 1999.

[42] Blöchl P. E., Projector augmented-wave method, Phys. Rev. B, 50 (24), 17953-17979, 1994.
[43] Perdew J. P., Burke K., Ernzerhof M., Generalized Gradient Approximation Made Simple, Phys. Rev. Lett., 77 (18), 3865-3868, 1996.

[44] Pack J. D., Monkhorst H. J., Special points for Brillouin-zone integrations-a reply, Phys. Rev. B, 16 (4), 1748-1749, 1977.

[45] Momma K., Izumi F., VESTA 3 for three-dimensional visualization of crystal, volumetric and morphology data, J. Appl. Crystallogr., 44 (6), 1272-1276, 2011.

[46] Le Page Y., Saxe P., Symmetry-general least-squares extraction of elastic data for strained materials from ab initio calculations of stress, Phys. Rev. B, 65 (10), 104104/1-14, 2002.

[47] Gaillac R., Pullumbi P., Coudert F.-X., ELATE: An open-source online application for analysis and visualization of elastic tensors, J. Phys. Condens. Matter, 28 (27), 275201/1-5, 2016.

[48] Blanco M. A., Francisco E., Luaña V., GIBBS: Isothermal-isobaric thermodynamics of solids from energy curves using a quasi-harmonic Debye model, Comput. Phys. Commun., 158 (1), 57-72, 2004.

[49] Woolfson M. M., Solid state physics 3. theory of lattice dynamics in the harmonic approximation, Acta Crystallogr. Sect. A, 29 (3), 314-314, 1973.

[50] Born M., On the stability of crystal lattices, I, Math. Proc. Cambridge Philos. Soc., 36 (2), 160-172, 1940.

[51] Mouhat F., Coudert F.-X., Necessary and sufficient elastic stability conditions in various crystal systems, Phys. Rev. B, 90 (22), 224104/1-4, 2014.

[52] Surucu G., Colakoglu K., Deligoz E., Korozlu N., FirstPrinciples Study on the MAX Phases $\mathrm{Ti}_{n+1} \mathrm{GaN}_{\mathrm{n}}(\mathrm{n}=1,2$ and 3), J. Electron. Mater. 45 (8), 4256-4264, 2016.

[53] Baysal M. B., Surucu G., Deligoz E., Ozısık H., The effect of hydrogen on the electronic, mechanical and phonon properties of $\mathrm{LaMgNi}_{4}$ and its hydrides for hydrogen storage applications, Int. J. Hydrogen Energy, 43 (52), 23397-23408, 2018.

[54] Flórez M., Recio J. M., Francisco E., Blanco M. A., Pendás A. M., First-principles study of the rocksalt-cesium chloride relative phase stability in alkali halides, Phys. Rev. B - Condens. Matter Mater. Phys., 66 (14), 1-8, 2002. 